\title{
مفهوم الذات لاي أمهات الأطفال المتلعثمين
}

إعداد

الباحثة / دينا رمضان عحم أحمد '

\author{
د/ هبه اسماعيل متولى \\ مدرس بقسم العلوم النفسية \\ كلية التربية للطفولة المبكرة \\ جامعة القاهرة
}

$$
\text { إثر افـ }
$$

\author{
أ.د/سهير أحمد كامل

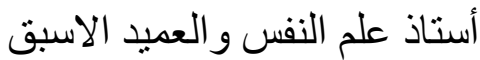 \\ كلية التربية للطفولة المبكرة \\ جامعة القاهرة
}

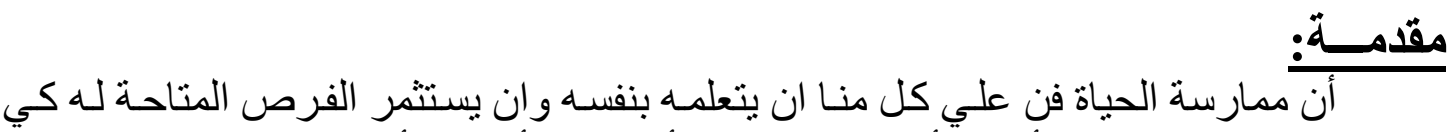

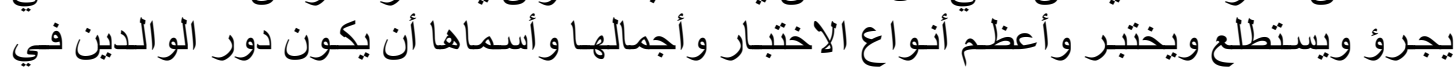
تعاملهم مع أطفالهم لكي يكونو الكئ حصنا لهم داخل المجتمع .

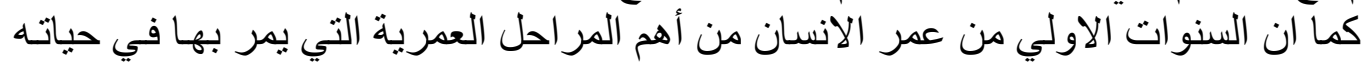

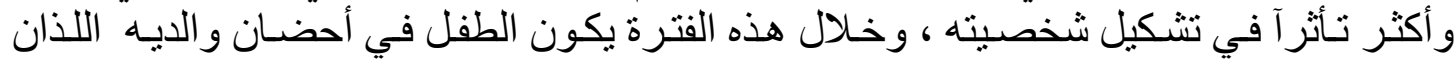

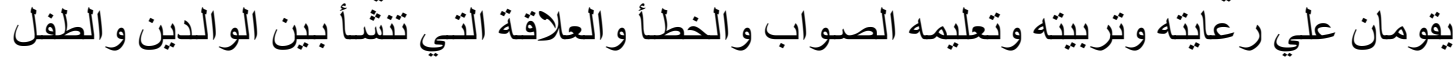

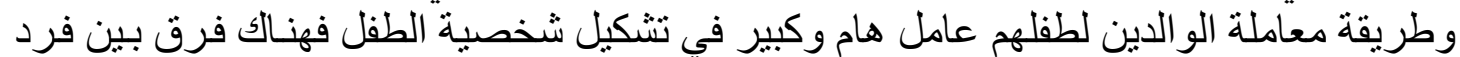

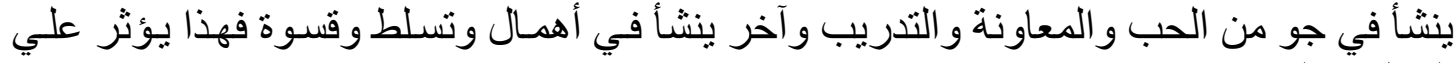

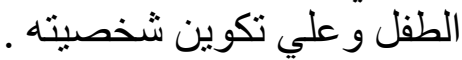

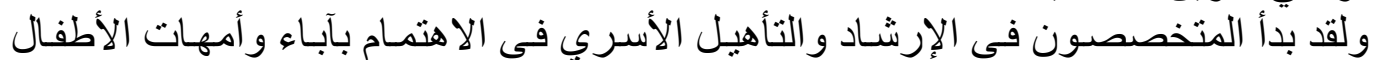

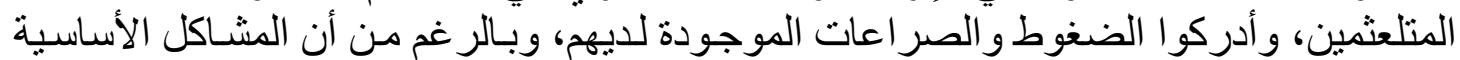

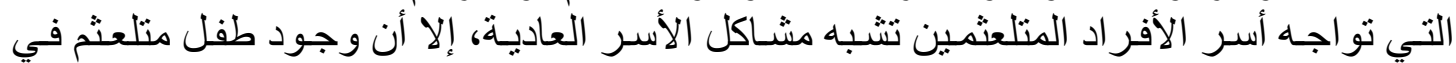

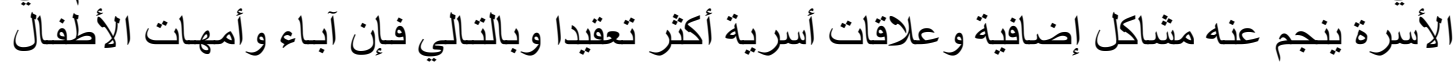

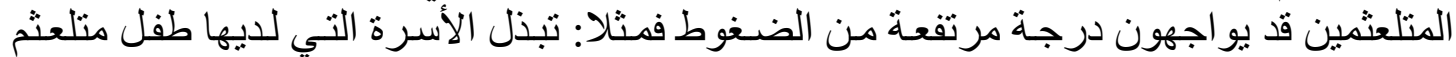
طاقة كبيرة ليظهر الطفل بصورة مقبولة أمام الناس، حيث تهنت هذئ هذه الأسرة اهتمامـا كبير ا بردود

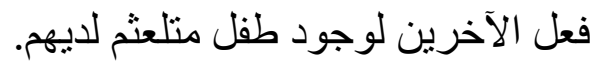
وقد لوحظ أن وجود الطفل المتلعثم يؤثر علي بنية الأسرة بأربع طرق إذ تثنير انفعالات قويـة

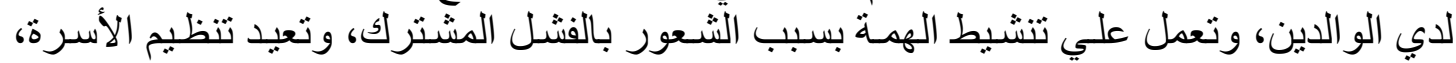

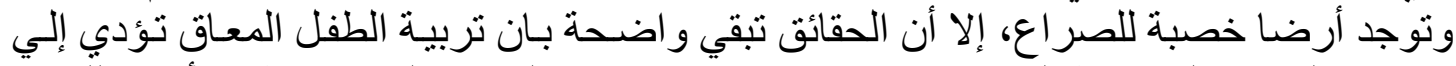

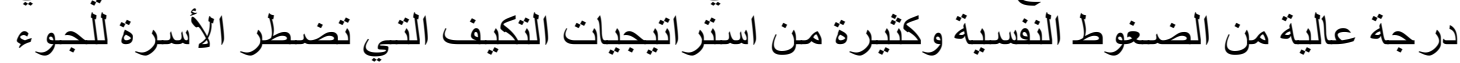

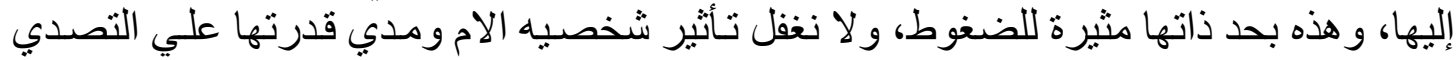
للمشكلات و المرونه في مو اجهه المو اقفا مثن الصعبه. 
مشاء الاحساسله البحث:

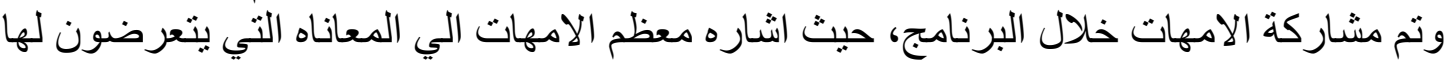

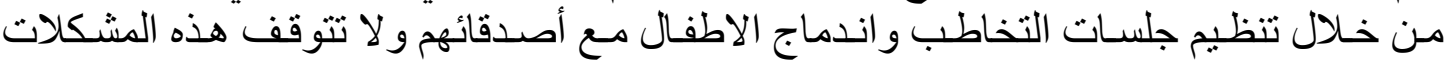

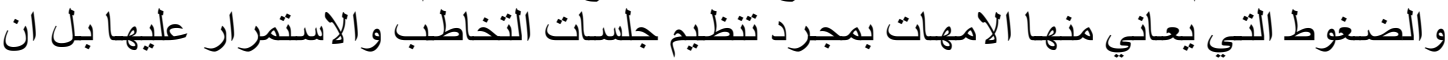

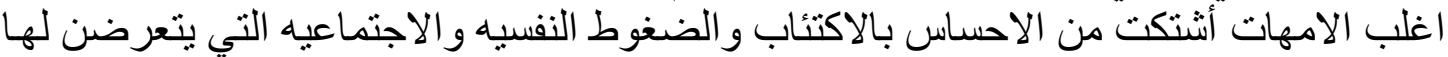

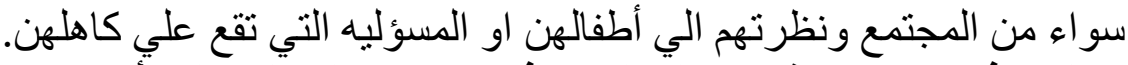

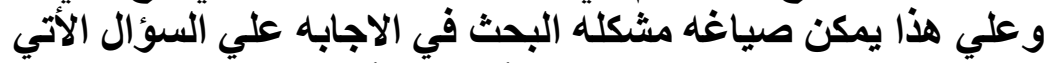

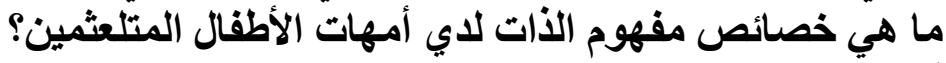

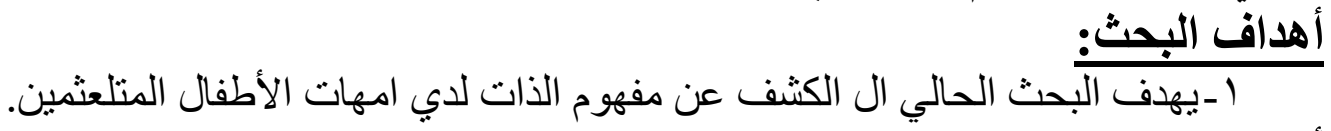
أهيه البحثث:

الأهمية النظرية:

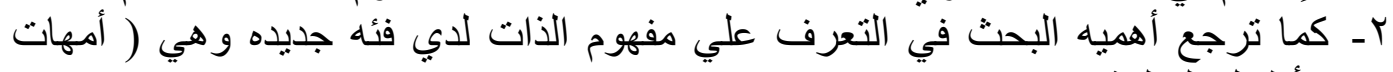
الأطفال المتلحثمين ).

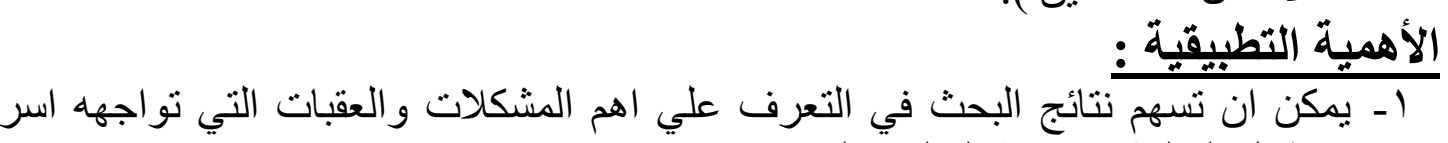

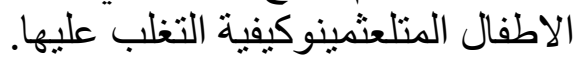

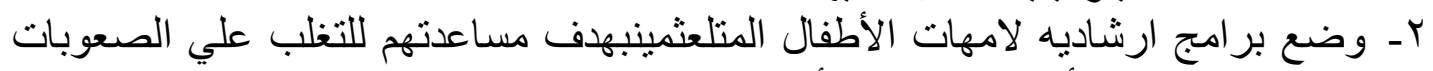

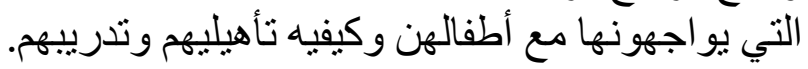
مفهوم الذات البحث:

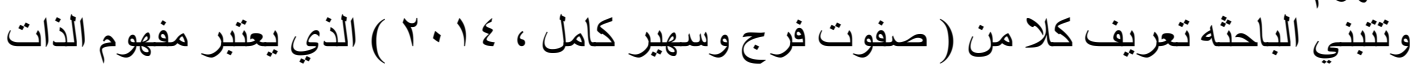

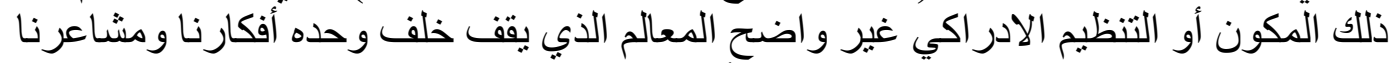

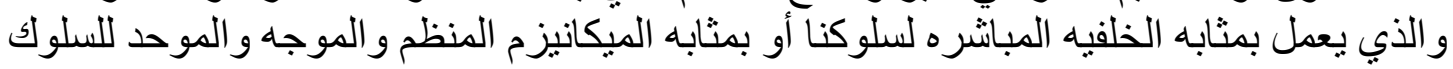

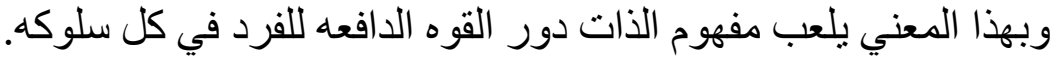

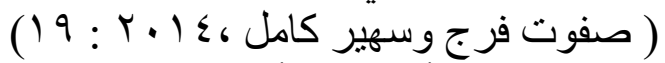

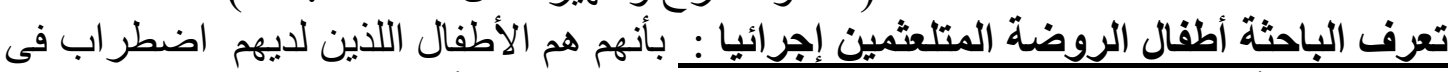

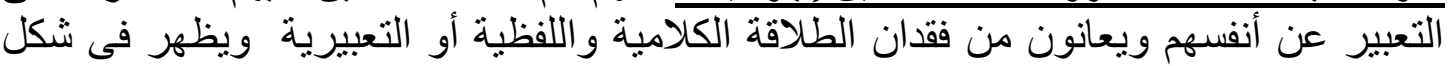

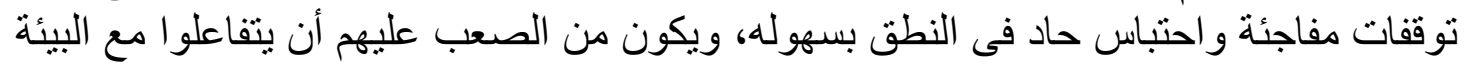
الإطيطة بيهم تفاعلا ايجابيا .

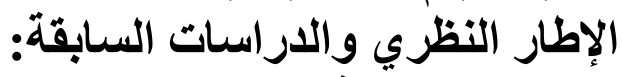
تعريفات مفهوم الأات: عرفت مفهوم الذات بأنّه ذلك التهات المكون أو التنظيم الادر اكي غير واضح المعالم الذي يقف خلف

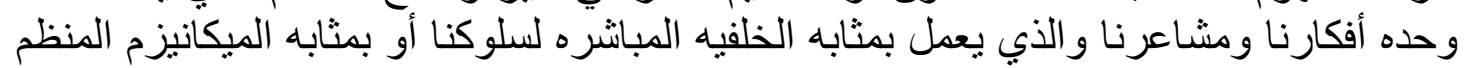
و الموجه و الموحد للسلوك وبهذا المعني يلعبب مفهوم الذات دور القوه القوه الدافعه للفرد في كل سلوكه.

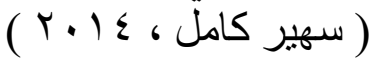

وعرفه بأنه "مجمل المنظومة المنظومة المعقدة والديناميكية للمعتقدات والزفاهيم والآراء المكتسبة التي يحملها الفرد حول حقيقة وجوده الثخصي، ونفية ونرتبط بالمستويات الأساسية من

(Oyserman, Elmore, \& Smith, 2019) 
و عرفه بأنه "تقييم الفرد لذاته في المجالات التي يعتبر فيها النجاح عنصر هام، وهي جميع المعتقدات التي تنشأ لديه حول سمأته الشخصية". و عرفه بأنه "مزيج من مفاهيم وقيم الفرد نحو نفسه، و التي تُبنى من خلال التفاعلات الإجنماعية". (Bong, \& Skaalvik, 2019) و عرفه بأنه "آلية معرفية تسمح بتشكيل العناصر المنظومية والإجتماعية والخبر ات المميزة للذات". (Gregg, 2020)

$$
\text { برى "كارل مفهوم الذات: }
$$
ـ ـ الذات الو اقعية : وهى اد ارك الفرد لقد ارتهه ومكانتة و ادو اره فى العالم الخارجى. ـ ـ الذات الاجتماعية : وهى الذات كما يعتقد الثخص ان الاخرين يرونها. ـ الذات الاد اركية : وهى عبارة عن تنظيم للاتجاهات الذاتية. ـ الذات المثالية : وهى مفهوم الفرد لذاته كما يود ان تكون عليه .

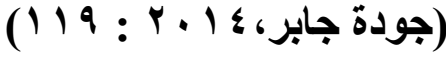

خصائص مفهوم الأت: وقد تم تحديد سبعه خصوم خصائص التاسية لمفهوم الذات:

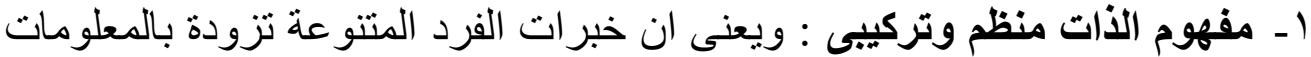

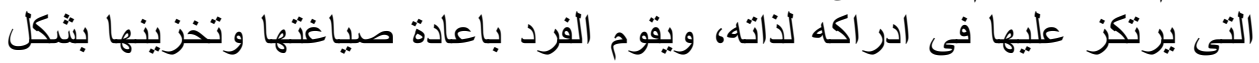

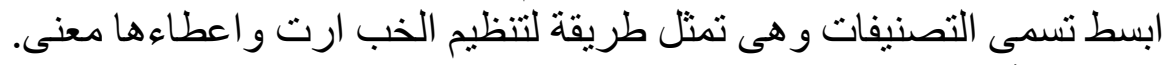

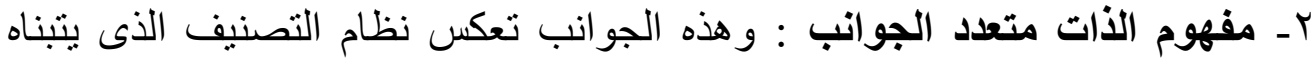
الفرد او يشاركة فيه العديدون و اشارت بعض الد ارسات الى ان نظام التصنيف هذا

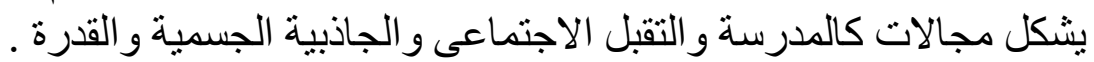

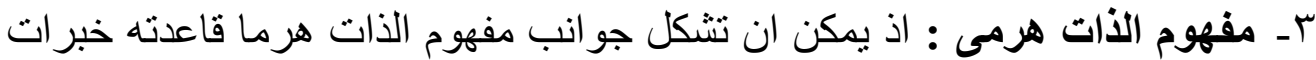

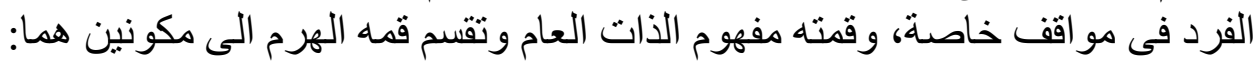

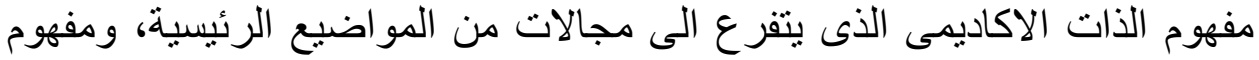

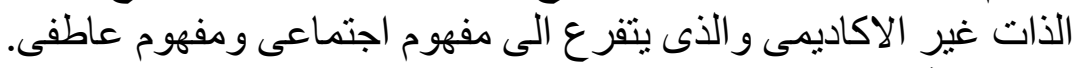

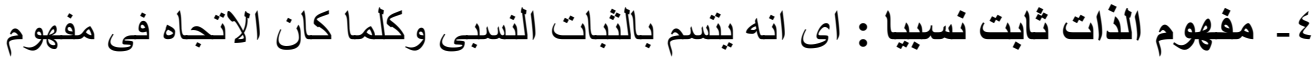

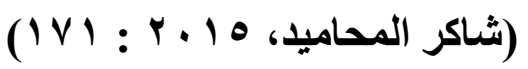
الذات نحو القاعدة كان هذا المفهوم اكثر ثباتا نسبيا. 0ـ مفهوم الذات نمائى ومتطور: فالاطفال لايميزون فى بداية حياتهم انفسهم عن البيئة

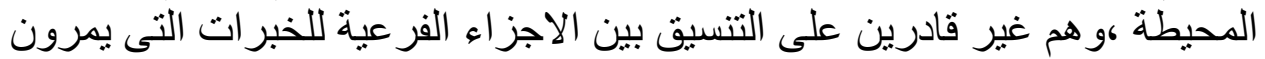

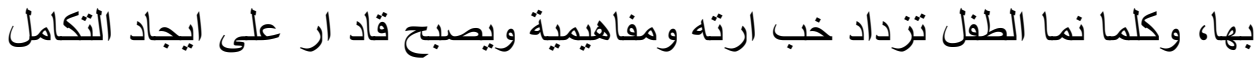

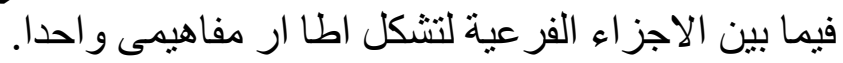
7- مفهوم الأت فارقىى: بمعنى انه متماري او مستقلا عن الابنية الاخرى التى التى تربطه

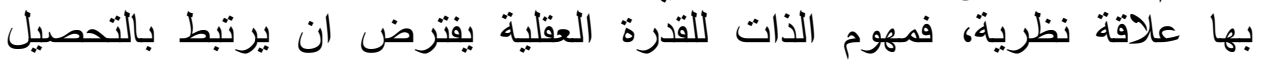

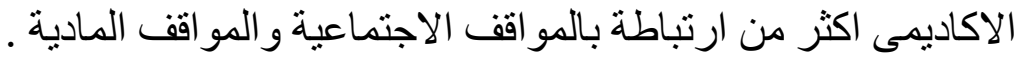

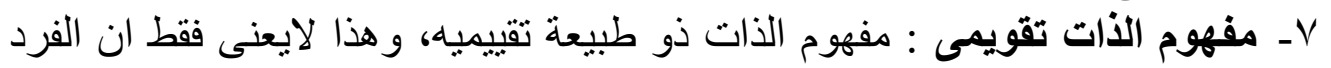

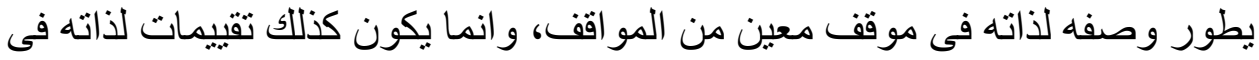
تللك المو اقف، ويمكن ان تصدر تللك التقييمات بالاشارة الى معايير مطلقة كالمقارنة 
المثالية، او يمكنه ان يعدد تقيماته بالاشارة الى معايير نسبية كالمقارنة مع الزمانداء

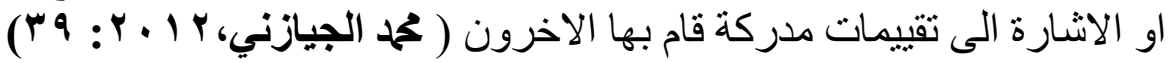

\section{خصائص أمهات الأطفال المتلعثمين:}

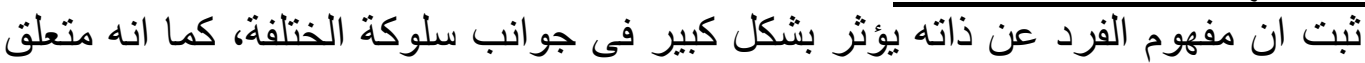

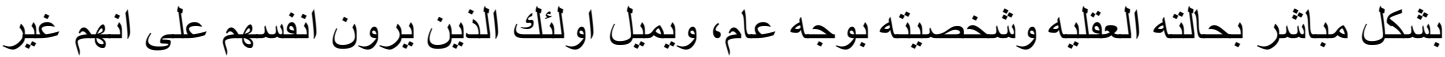

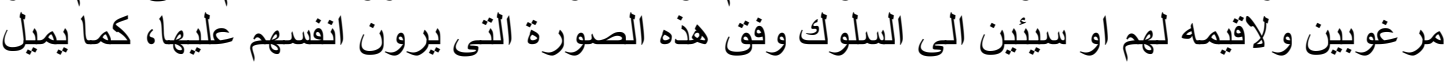

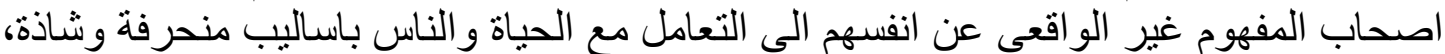

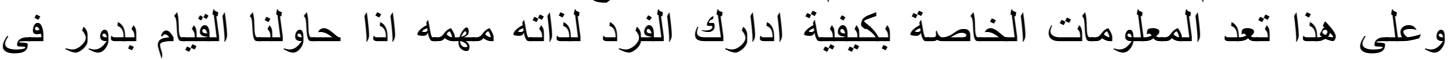

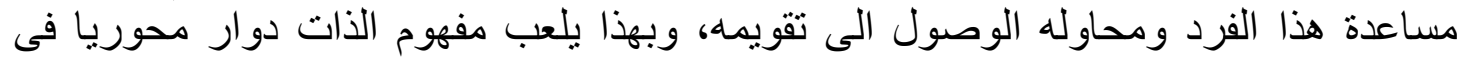

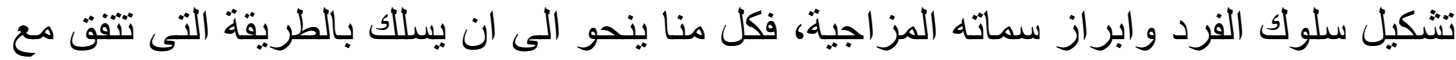

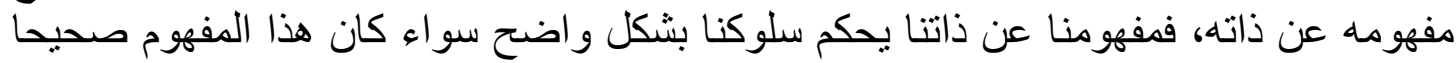

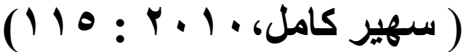

او خاطئا

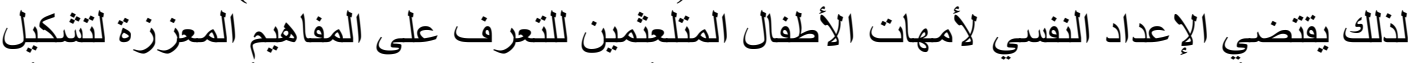

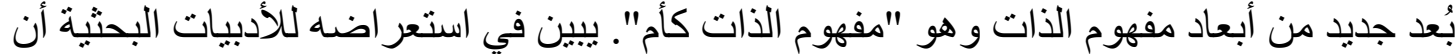

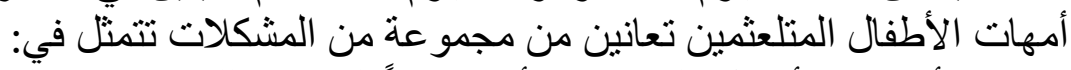
( ) أمهات الأطفال المتلعثمين أكثر ميلاً لتوجيه اللوم التهن للذات بالّمقارنة مع أمهات الأطفال

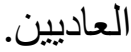

r) أمهات الأطفال المتلعثمين تعانين من تدهور جودة الحياة الأسرية وتوفير البيئة المستقرة

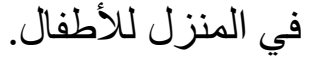

ץ) تكر ار المشكلات الوجدانية بين أمهات الأطفال المتلعثمين وهلى رأسها مشاعر الإحباط و الذنب و القلق و الخوف حول تلعثم الطفل.

ع) يؤدي التلعثم بين الأطفال إلى انخفاض الوظئ لإليفية الإجتماعية للأمهات والأسرة بصفة عامة نتيجة للشعور بالإحر اج أو الخجل في المواقف الخفالف العامة. 0) أمهات الأطفال المتلعثمين لايهن مستويات مرتفعة من الإحتر اق النفسي. (Jones, \& Prinz, 2017, 341)

ويثير إلى أن آباء الأطفال المتلعثمين وبصفة خاصة الأمهات يُظهرون أعر اض العُصابية و التي

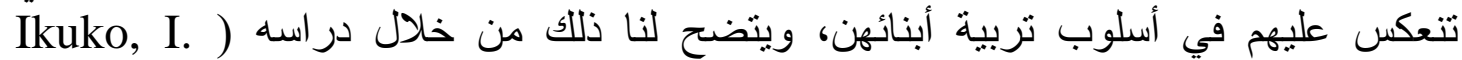
Change In Self-Concept In Mothers Of Stuttering Children - ((2019).

From Both Positive Experiences And Negative Experiences, بعنوان التغيرات في مفهوم الذات بين أمهات الأطفال المتلعثمين: استعر اض الخبرات الإيجابية

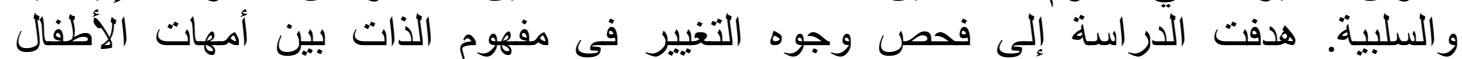

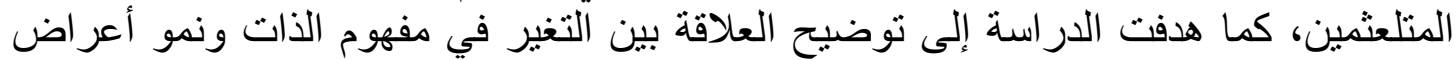

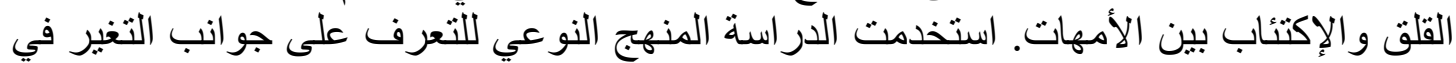

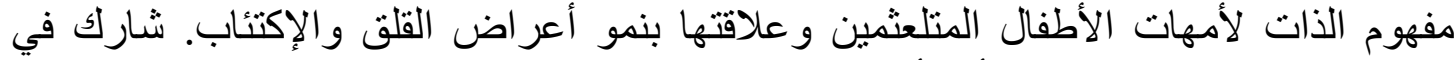

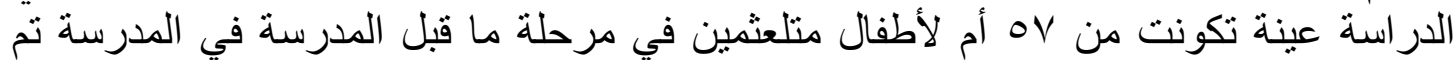

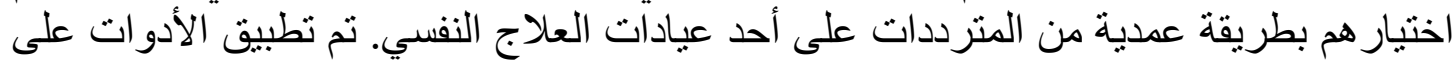

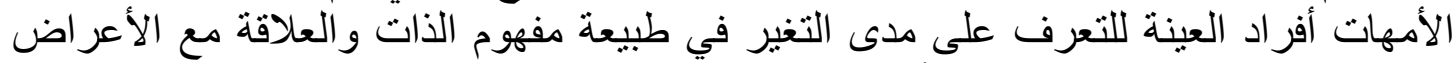

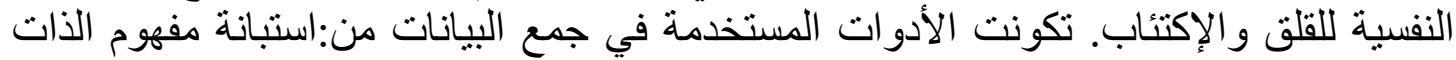

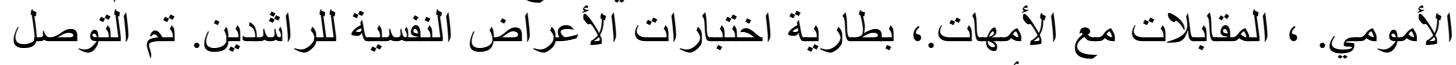

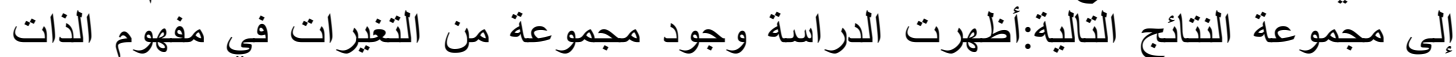

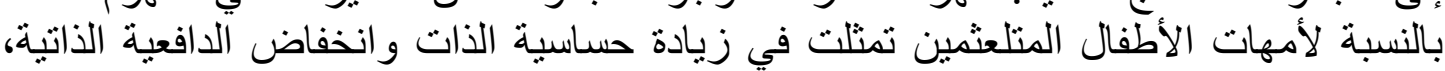




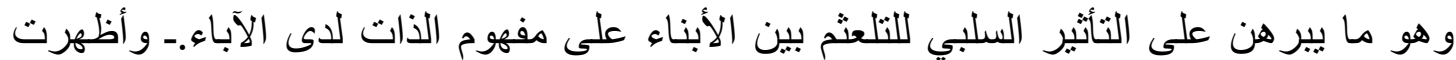

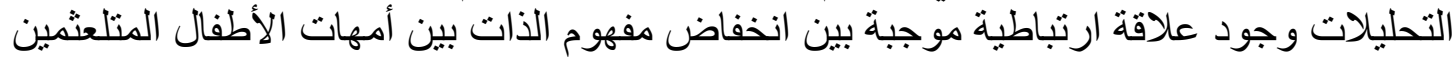

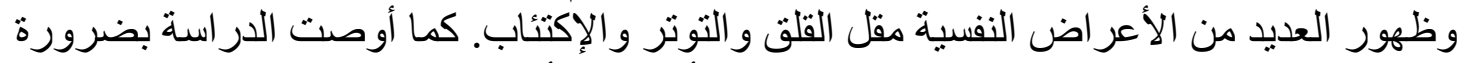

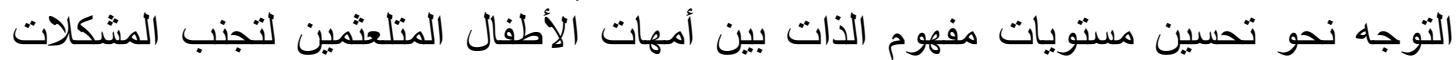

الأساس النظري لمفهوم الذات بين أمهات الأطفال المتلعثمين:

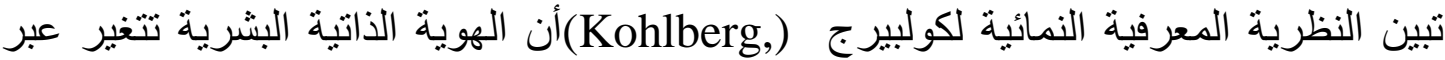

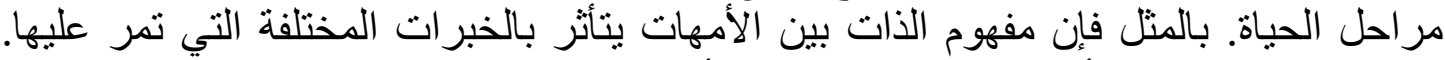

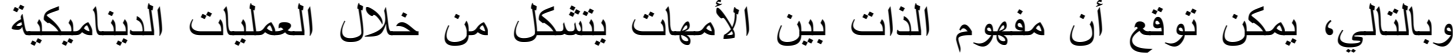

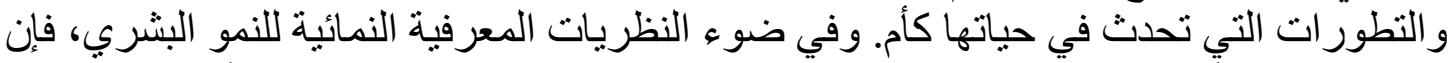

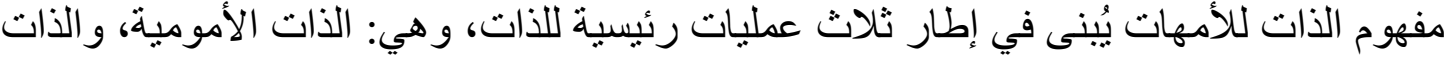
الفردية على المستوى الثهصي والذات في إطار العلاقات الإجتماعية

(Hartrick, 2018, 263)

بالتالي فإن مفهوم الذات يتسم بالديناميكية وتعقيد الأسباب المؤدية إليه، بمعنى أن المشكلات

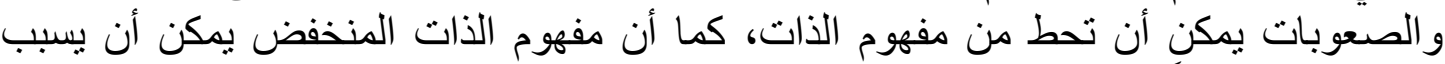

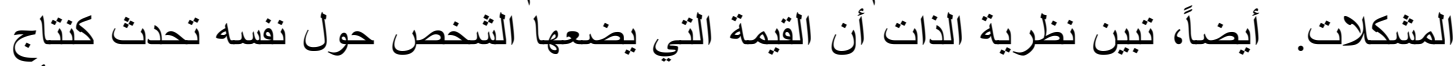

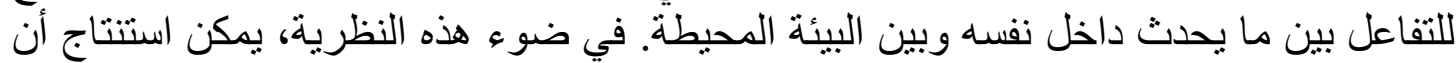

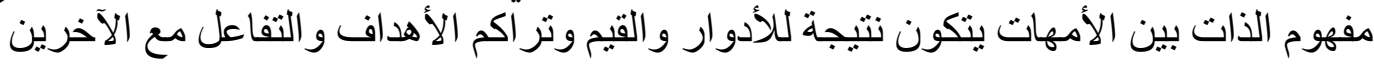

(Blood, Blood, Tellis, \& Gabel, 2018, 123)

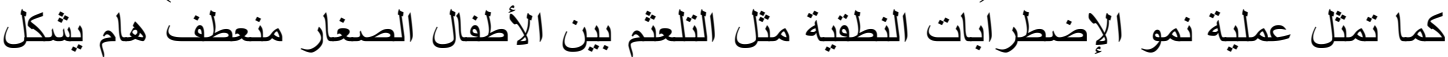

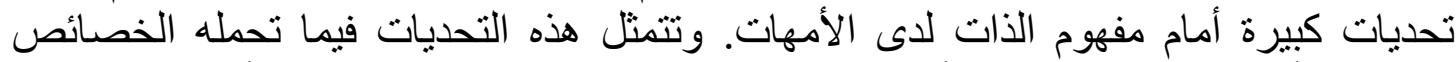

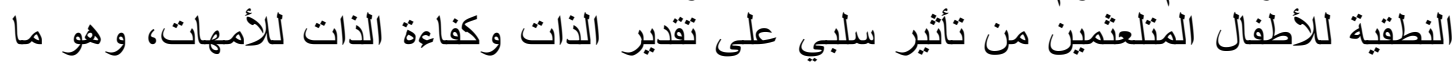

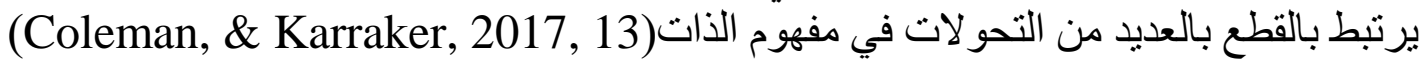
وهذا ما أكدات عليه دراسه . Self-Concept And Self- Wagnon, M. (2019) Efficacy In Mothers Of Young Children Who Stutter الأات وكفاءة الذات بين أمهات الأطفال المتلعثمين. هدفت الدراسة إلى مقارنة مفهوم الذات الذات

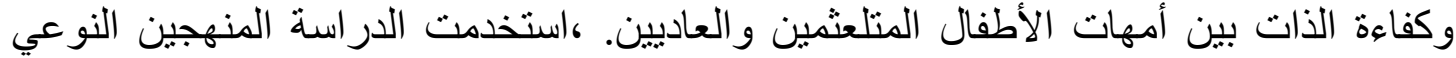

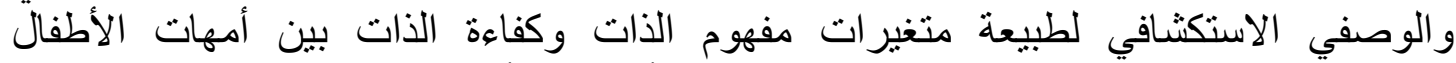

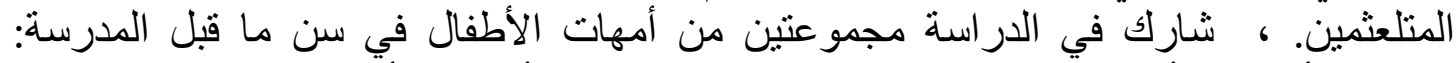

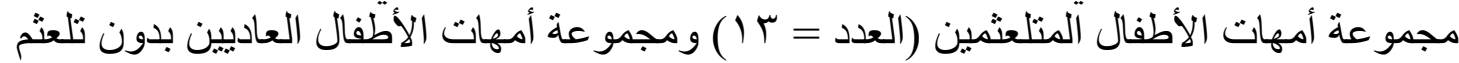

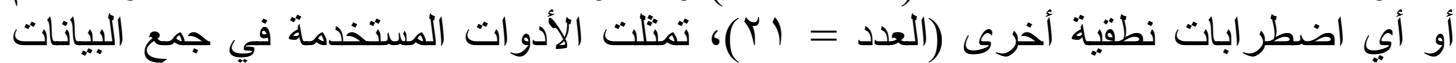

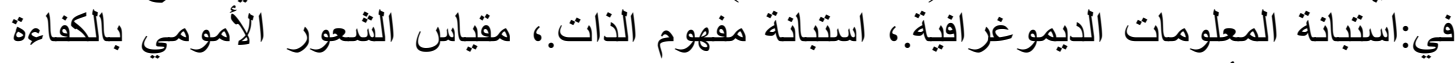
(POSC)

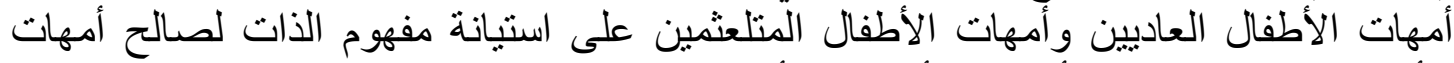

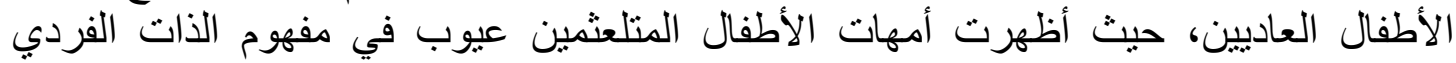

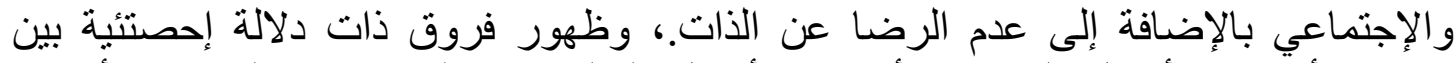

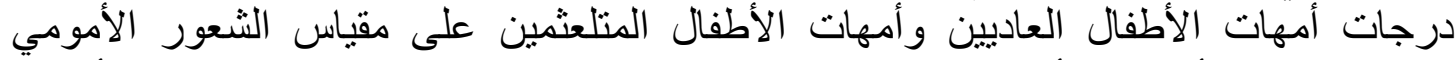

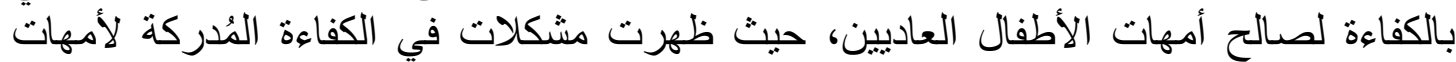

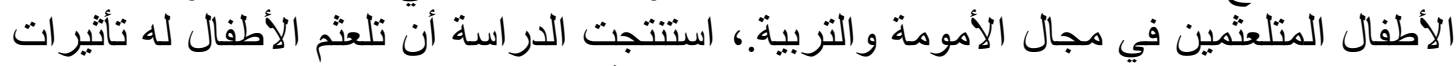
سلبية على كل من مفهوم الذات وكفاءة الذات المُدركة للأمهات. 
مفهوم الأات بين أمهات الأطفال المتلعثمين:

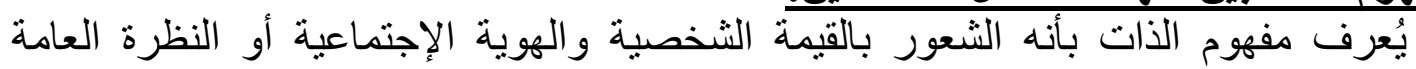

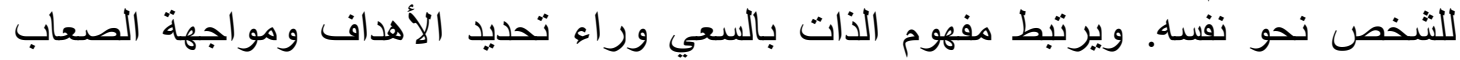

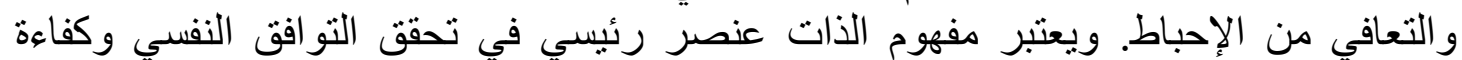

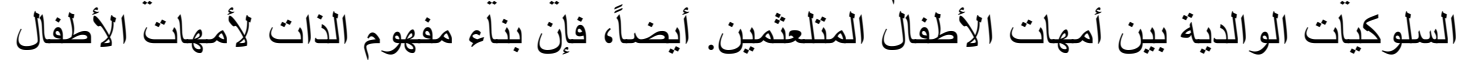

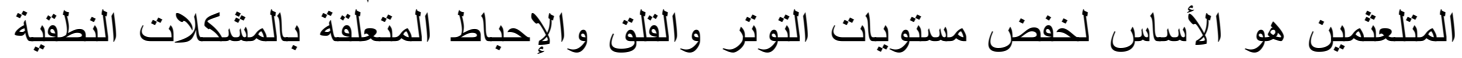

(Millard, \& Davis, 2018. 950)

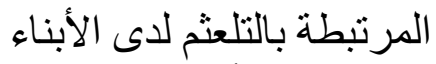

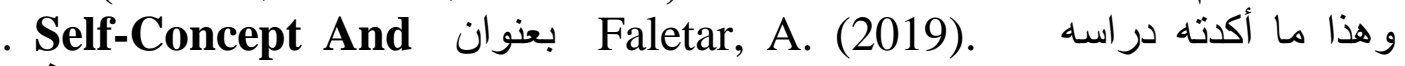
Quality of Life of Mothers of Children Who Stutter وجودة الحياة بين أمهات الأطفال المتلعثمين، هدفت الدر اسة إلى التعرف على تأثير تلعثم أطفال

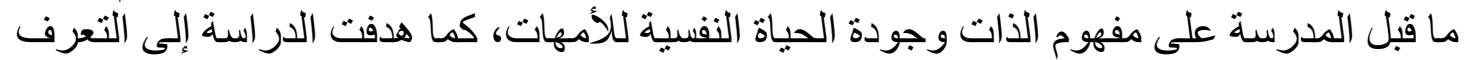

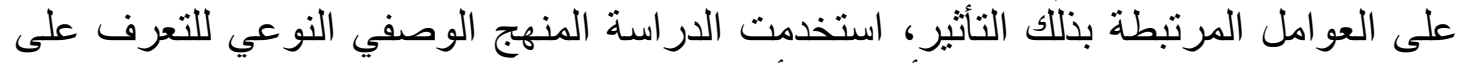

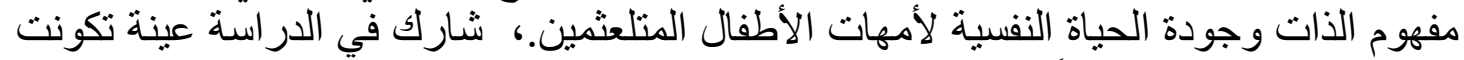

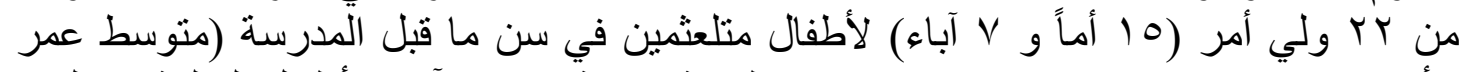

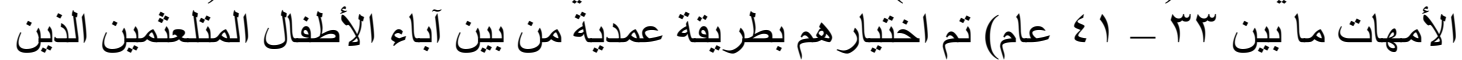

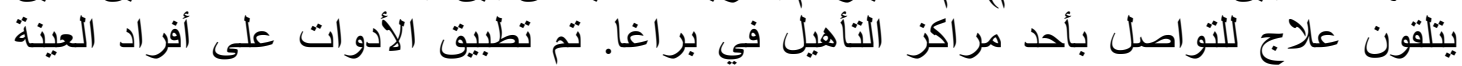

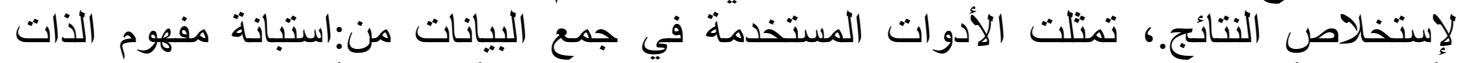

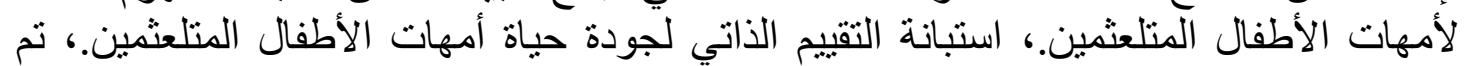

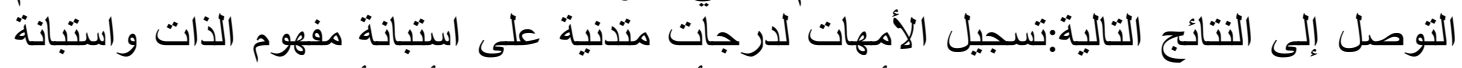

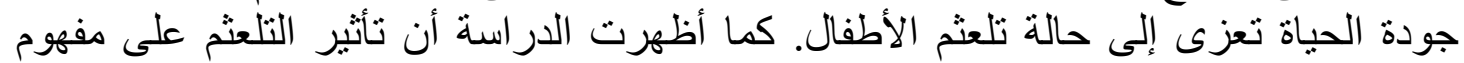

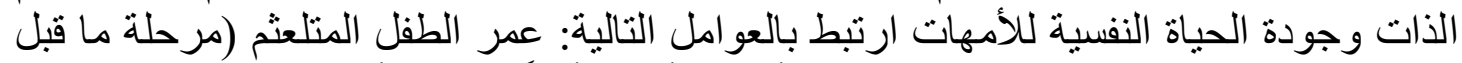
المدرسة) وشدة تلعثم الطفل ونوع الآباء (الأمهات أكثر تأثر اً بتلعثم الأطفال فيما يتعلق بمفهوم الذات وجودة الحياة النفسية).

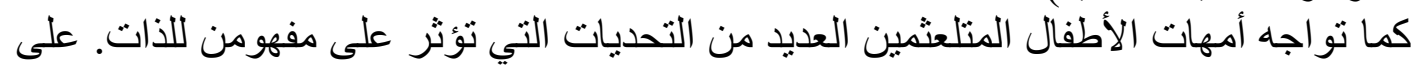

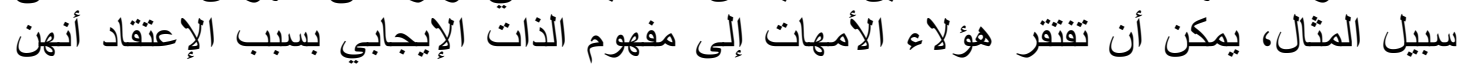

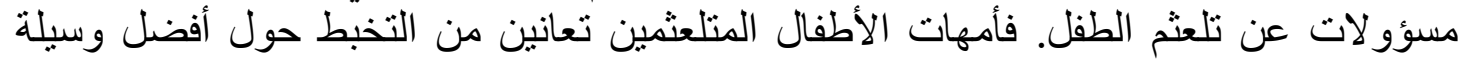

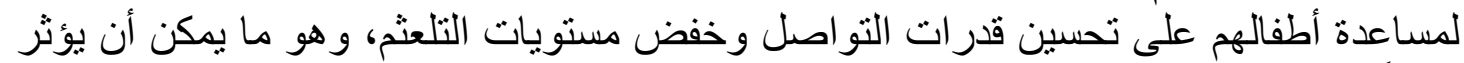

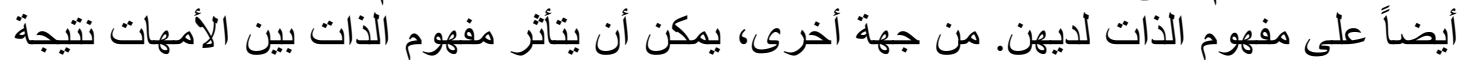

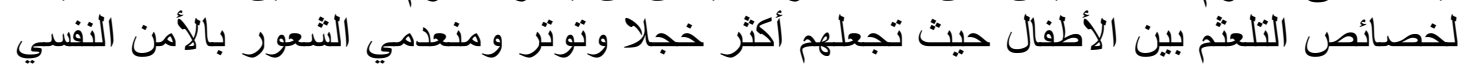

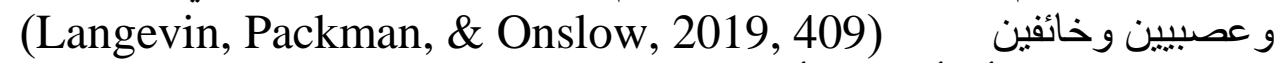

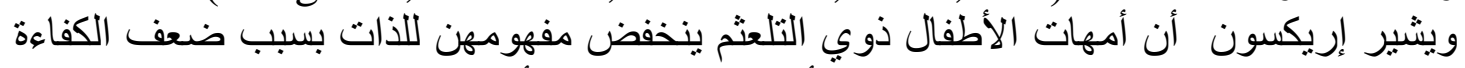

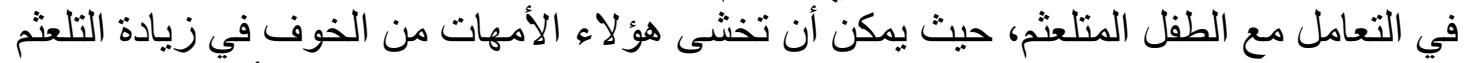

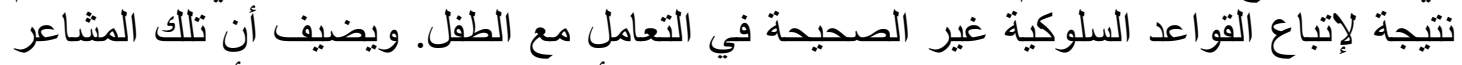
الخاصة بالثك والخوف والتخف اعذاض الثقة في مساعدة الأطفال المتلعثمين بمكن أن تدمر مفهوم

(Erickson, \& Block, 2019, 311)

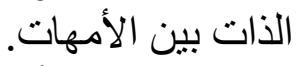
ويمكن تصنيف أهم أسباب عيوب مفهوم الأات التي تواجه أمهات الأطفال المتلعثمين وفقاً لـ

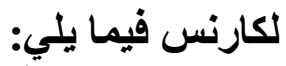
() تلعثم الطقل: تتضمن توثر وقلق الأمهات بسبب صعوبة النطق والتو اصل و عجز قدرتهم على التكيف مع المحيط الذي يعيشون فيه بسبب مظاهر التلعثم مثل تبديل الأصوات التهن

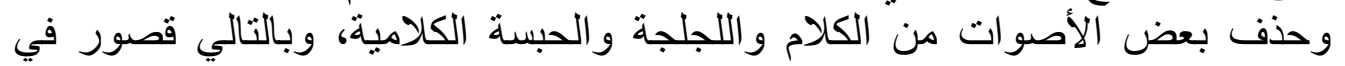
قدر ات التواصل الفعال في التعامل الإيجابي مع المحيطين بالطفل. 
Y (Yحمل أعباء الطفل المالية: يؤثر الطفل المتلعثم على الأوضاع الاقتصادية للأسرة، حيث

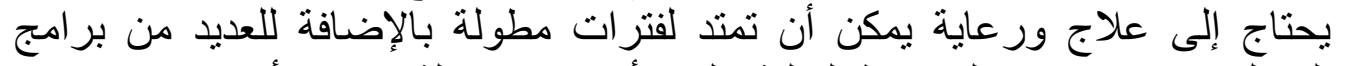

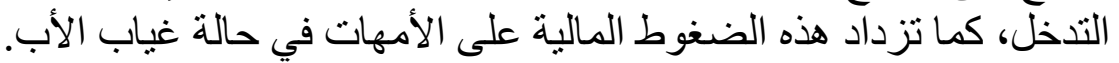

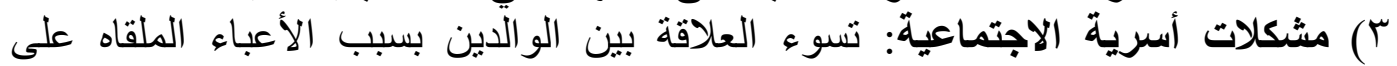

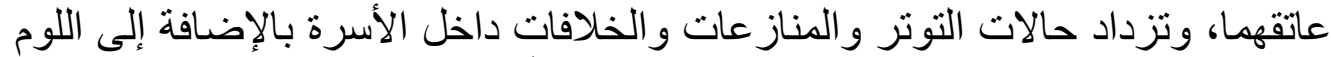

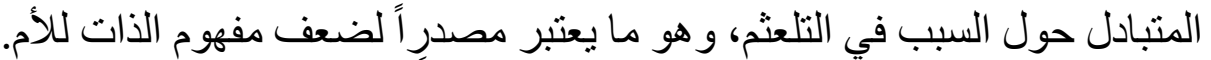

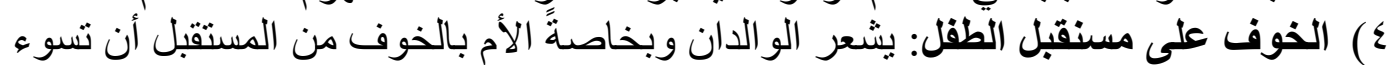

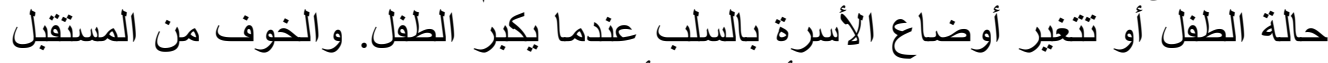

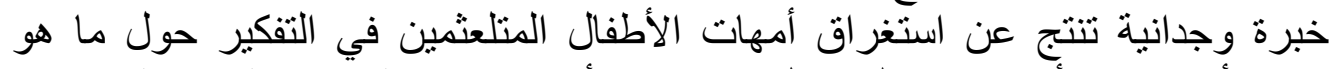

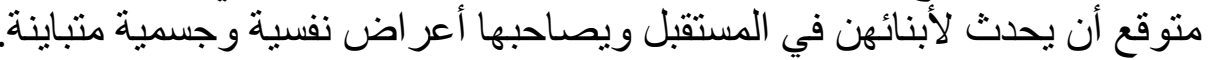
0) الأعراض النفسية للأمهات: تتعرض الأن الأم بصفة خاصة للتوتر و القلق و الإحباط الناتج عن التأثير ات السلبية لسلوك و الخصائص النمائية للطفل المتلعثم وكثر متطلباته.

(Crncec, Barnett, \& Matthey, 2020, 210 )

أيضاً ذكر ــ ديسجاردن - أن حالة تلعثم الأطفال الصغار تؤثر على الأبعاد التالية لمفهوم الذات

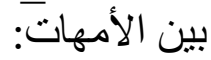
( ) مفهوم الذات التأثيرية: المشاعر حول الأمومة.

r) مفهوم الذات المعرفية: المفاهيم حول أدوار الأمواتة الأموة. (DesJardin, 2018, 193) بالإضافة لذللك، يشير إلى وجود جوانب قصور في أنواع مفهوم الذات التالية لأمهات الأطفال

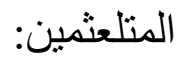
( ) مفهوم الذات الشخصي: شكل أو طبيعة تكوين الذات.

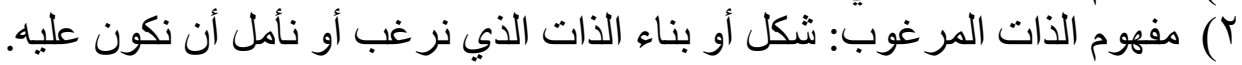

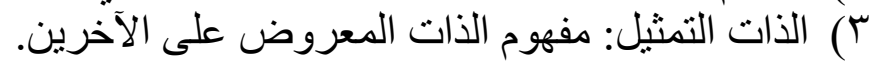

(Erickson, \& Block, 2018, 311)

ويرى جرلوا أن مفهوم الذات بين أمهات الأطفال المتلعثمين بمثل بناء اجتماعي ومعرفي و عاطفي يرتبط بقوة بتقييمات الأمهات حول قدر اتهن على إنجاز المهام الكهات الكنعلقة بأمومة الأنة الأطفال

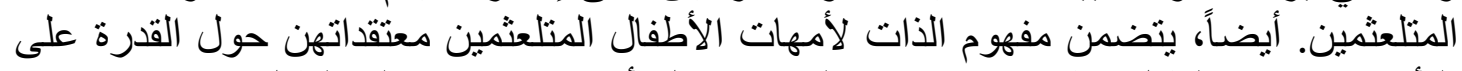

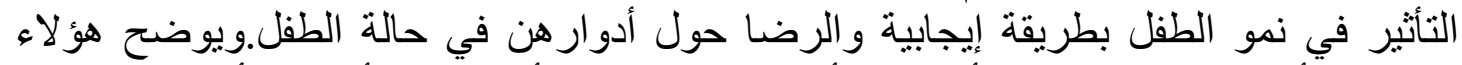

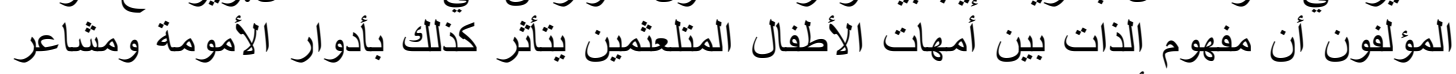

(Giallo, Wood, Jellett, \& Porter, 2017, 465) الكفاءة في العناية بالأطفال.

The Shaping of Motherhood: بعنوان Wagnon, M. (2018). وهذا ما تأكده در اسه How Raising a Child Who Stutters Impacts Self-Concept of Mothers بعنوان تشكيل الأمومة: تأثثر نربية الطفل المتلعثم على مفهوم الذات بين الأمهات، هدفت الدار استة

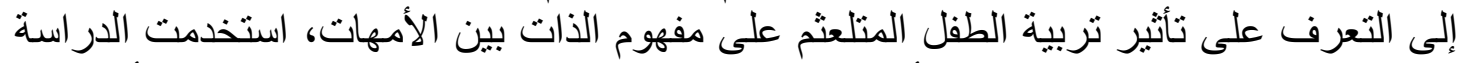

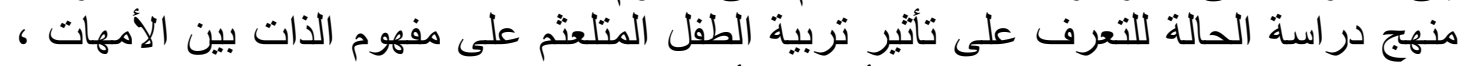

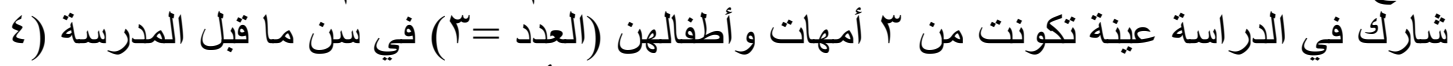

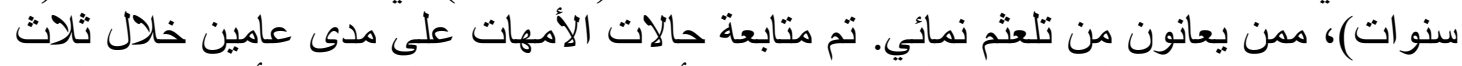

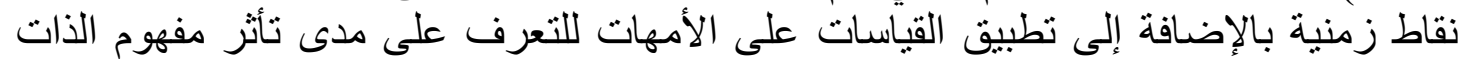

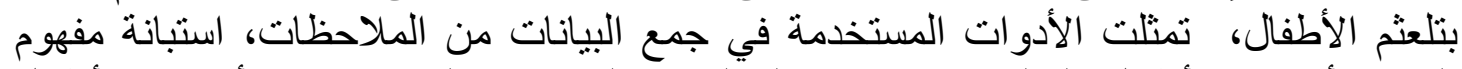

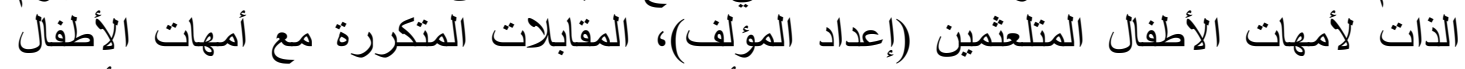

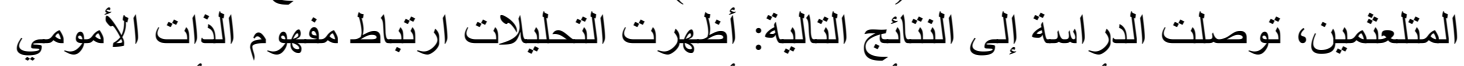

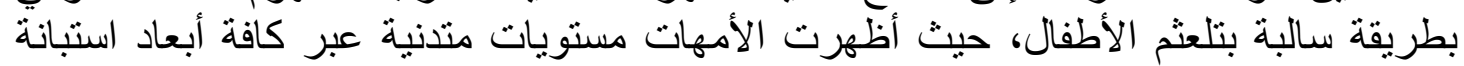

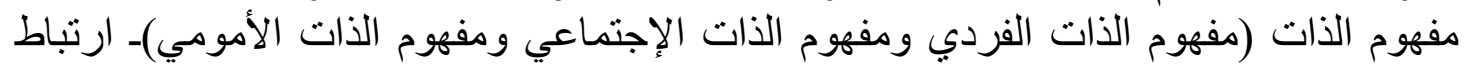


انخفاض مفهوم الذات بين الأمهات بالعديد من الأعراض النفسية السلبية (القلق والإحباط ولوم

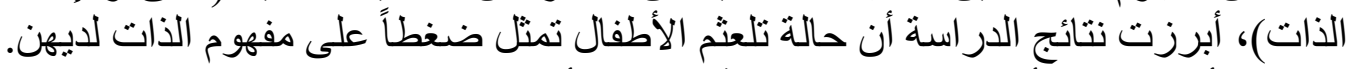

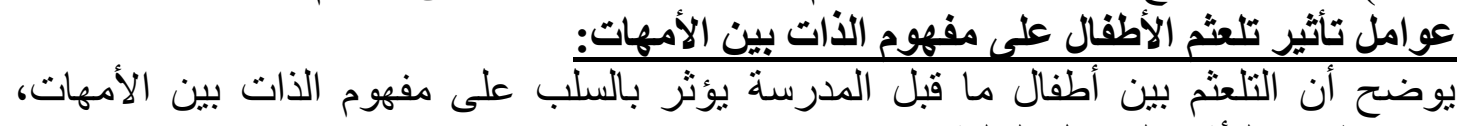
ويتوسط هذا التأثير العوامل التالية:

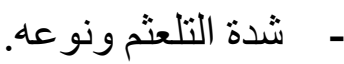

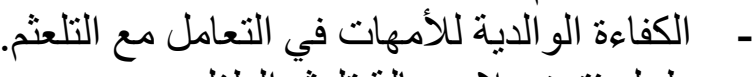

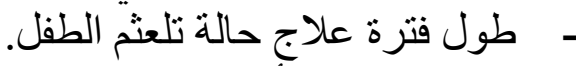

(Coleman, \& Karraker, 2018, 13) - مستوى تعليم الأمهات. كما أن مفهوم الذات بين أمهات الأطفال المتلعثمين يرتبط بالعلاقة بين الأم ـالطفل بالإضافة

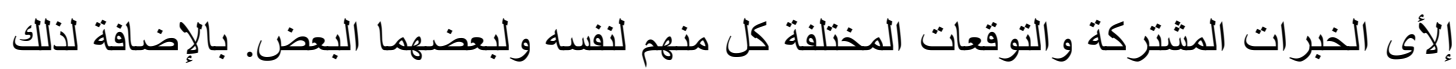

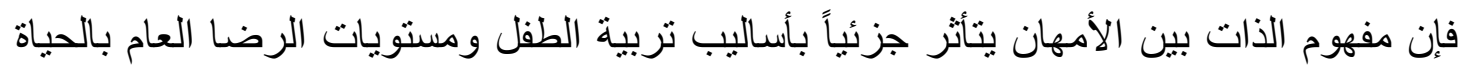
(Halpern, \& Mclean, 2018, 515) التي تسنشعر ها الأم. أهمية تحسين مفهوم الأت بين أمهات الأطفال المتلعثمين: يعتبر مفهوم الذات أحد أهم سمات الثخصية المرتبطة بالوجود البشري، والتي تتكون من خلال

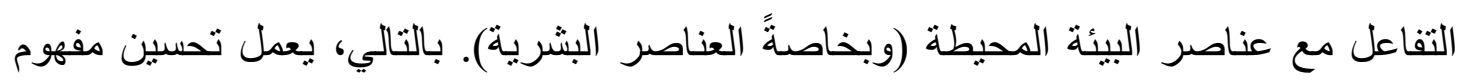
الذات بين أمهات الأطفال المتلعثمين إلى تحسين العديد من خصائصهن التوافقية وارتفاع مسنويات جودة الحياة والهوية الذاتية، وهو ما ينعكس أيضاً بالإيجاب على الطفل من خلال الطين

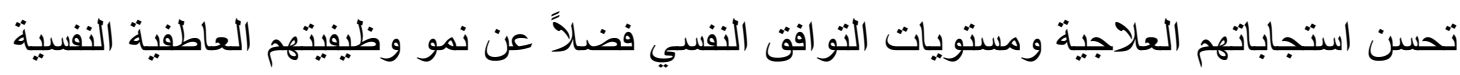

(Nunes, \& Ayala-Nunes, 2017, 32)

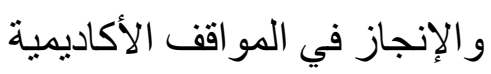
من جهة أخرى، فإن الأمهات ذات مستوى مفهوم الذات المرتفع يقدمون مستويات جيدة

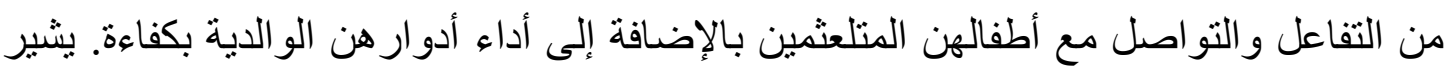
إلى وجود علاقة إيجابية بين مفهوم الذات العام المرتفع بين أمهات الأطفال المتلعثمين

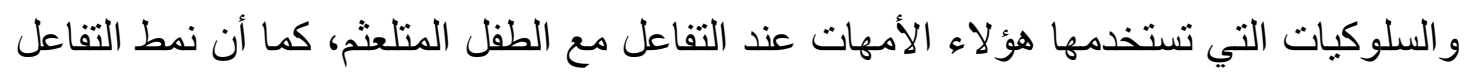
و التو اصل بين الأمهات ذات مفهوم الذات المرتفع و أطفالهن المتلعثمين ينسم بالإستجابة و الانتباه ( Yang, 2019, 6 ) والهدوء.

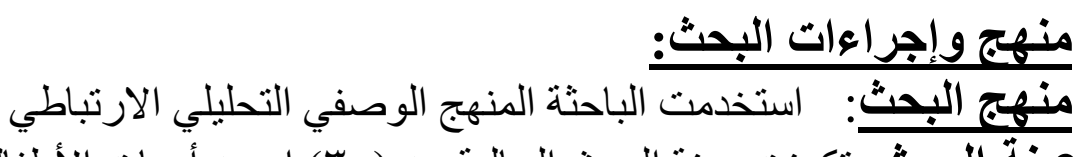

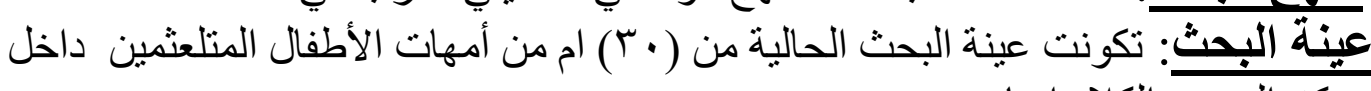

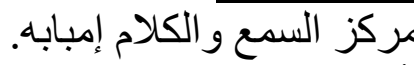
أدوات البحث: البمع:

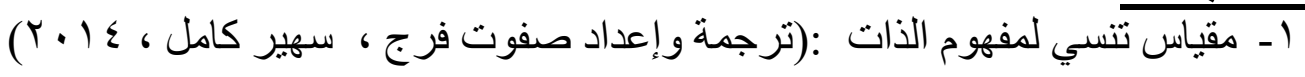


استخدم مقياس تنسى لمفهوم الذات، وهو مقياس متعدد الابعاد فى وصفه لمفهوم الذات

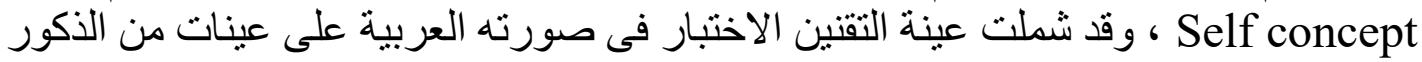

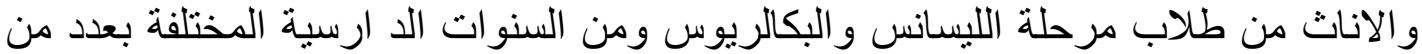

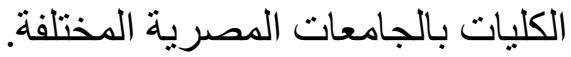

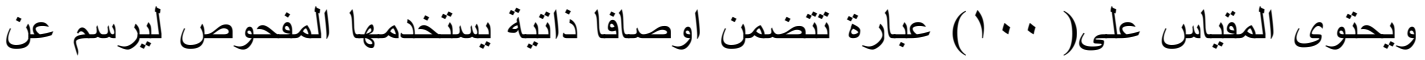

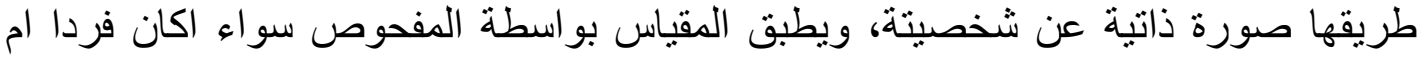

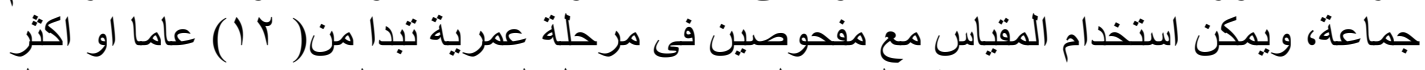

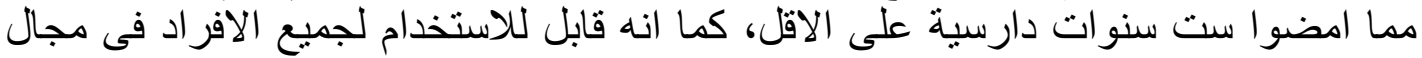

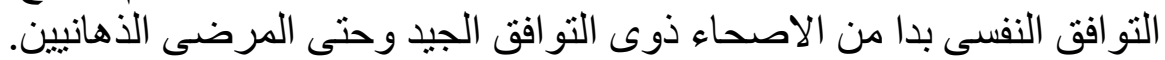

تجانس العينة

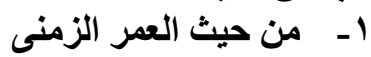

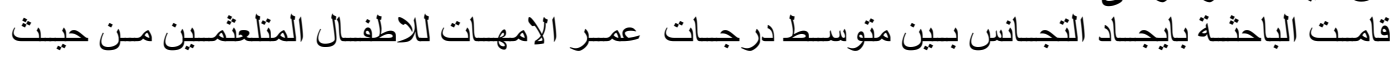

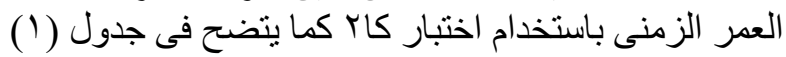

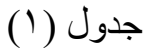

التجانس بين أمهات الأطفال المتلعثمين من حيث العمر الزمنى

$$
\text { r. }
$$

\begin{tabular}{|c|c|c|c|c|c|}
\hline \multicolumn{2}{|c|}{ حدود الدلالة } & درجة حرية & مستوى & كاr & المتغيرات \\
\hline .0 &. .1 & & & & \\
\hline Y. & rr & 17 & غير دالة & $0.1 \mu r$ & زمنح \\
\hline
\end{tabular}

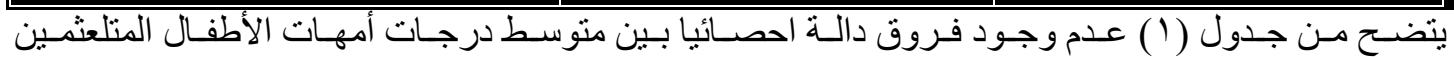

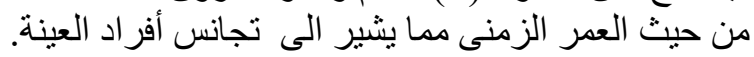

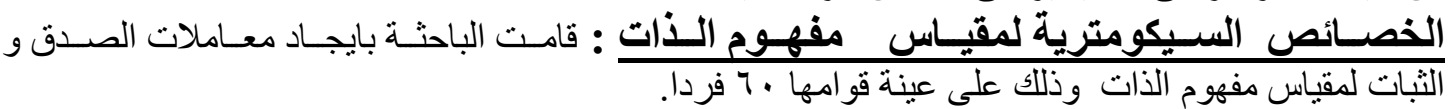

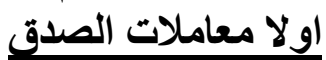
الصدق التصلازميى

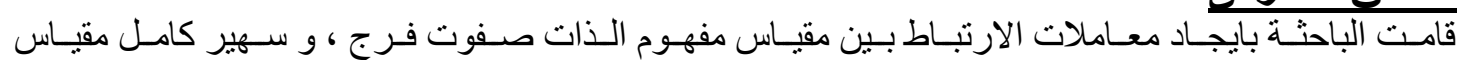

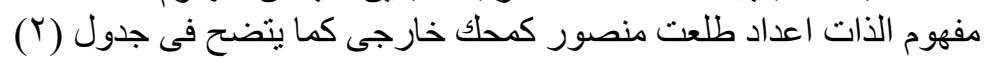
(r) جدول

معاملات الصدق لمقياس مفهوم الذات

\begin{tabular}{|c|c|}
\hline معامل الصدق & المتغير ات \\
\hline.$\wedge 9$ & الدرجة الكلية لمفهوم الذات \\
\hline
\end{tabular}

يتضح من جدول ( r ) ان قيم معاملات الصدق مرتفعة مما يدل على صدق المقياس

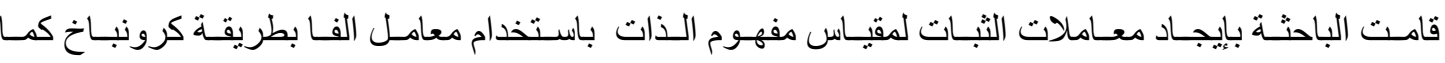

قامست الباحثة بإيجات الثبات

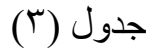

معاملات الثبات لمقياس مفهوم الذات

\begin{tabular}{|c|c|}
\hline معامل الثبات & المتغبر ات \\
\hline .99 & الدرجة الكلية لمفهوم الذات \\
\hline
\end{tabular}

بتضح من جدول ( r ) ان قيم معاملات الثبات مرتفعة مما يدل على ثبات المقياس 


\section{فروض البحث \\ الفرض الاول

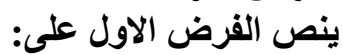

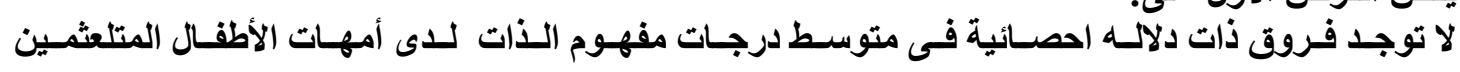
للتحقق من صحة ذلك الفرض استخدمت الباحثة اختبار ت للعينة الو احدة لايجـاد قيمت ت باستخدام المتوسط

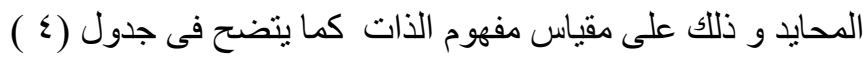

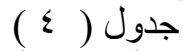

مفهوم الذات لدى أمهات الأطفال المتلعثمين

$r \cdot=ن$

\begin{tabular}{|c|c|c|c|c|c|c|}
\hline الالائة & مستوي & 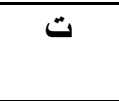 & المتوسطايد & الالنحرافياري & متوسطة & البعد \\
\hline في التجاه مفهوم للعاديين & مستوى دالة عند & r. Irq & 10. & $0 \wedge .94$ & IYV.1 & مفهوم الذات \\
\hline
\end{tabular}

$$
\begin{aligned}
& \text { ت = } \\
& \text { ت = 79. اعند مستوى } 0 \text {. }
\end{aligned}
$$

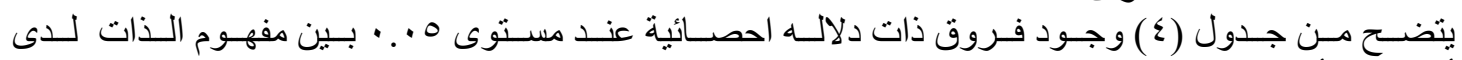

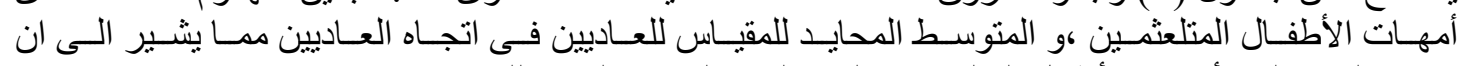

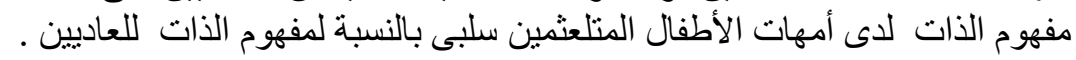

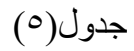

مفهوم الذات لاى امهات الاطفال المتلعثمين

\begin{tabular}{|c|c|c|}
\hline \multicolumn{2}{|c|}{ نتائج عينة البحث } & \multirow{2}{*}{ المقياس } \\
\hline$\varepsilon$ & 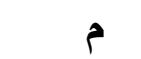 & \\
\hline $1 \cdot r V$ & 0.90 & الدفاعات الموجبة \\
\hline $9 . \mathrm{V}$ & $7 \varepsilon .1$ & سو ء التو افق العام \\
\hline M. $\leqslant q$ & $7 \cdot .50$ & الذهانية \\
\hline $1 \wedge . \leqslant \mu$ & $V 7 . \varepsilon$ & اضطر ابات الثخصية \\
\hline $\mid \leq .71$ & TY.r & العصابية \\
\hline 1.91 & $r .90$ & تكامل الثخصية \\
\hline
\end{tabular}

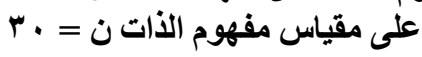

و يوضح شكل ( ) مفهوم الذات للى أمهات الأطفال المتلعثمين.

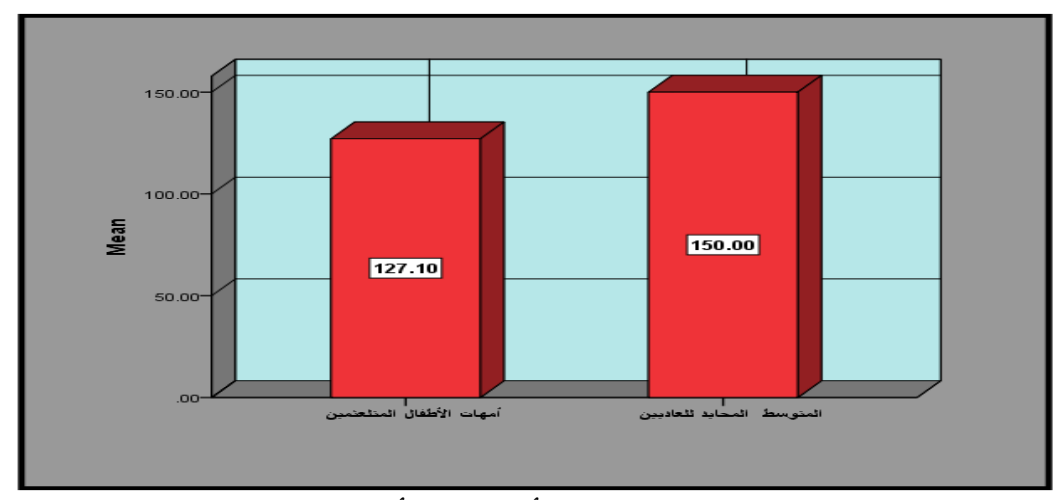

شكل (1) مفهوم الذات لدى أمهات الأطفال المتلعثمين 
اشارت نتائج الامهات على مقياس الدفاعات الموجبة الي ان المفحوصات لديهن فكرة

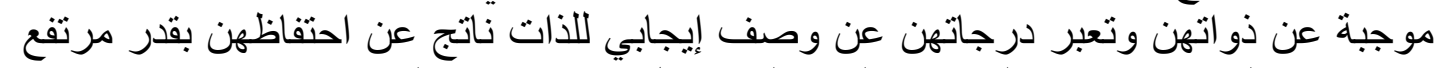

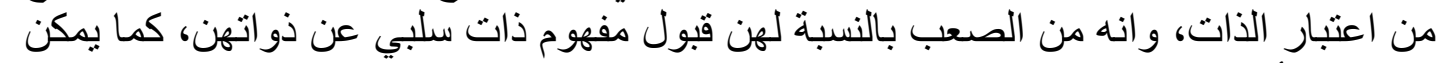

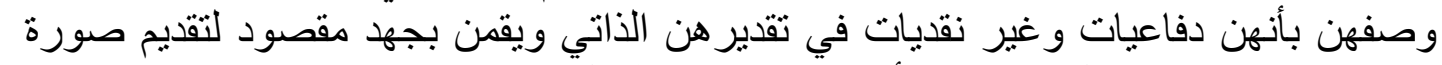

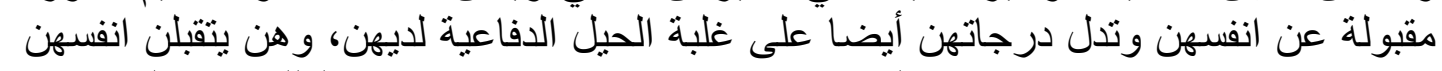

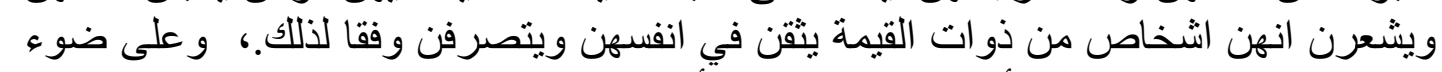

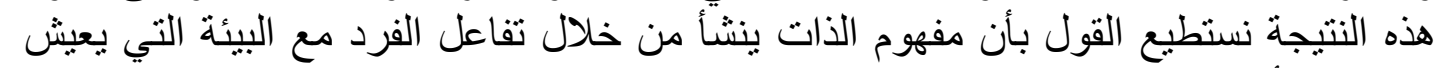

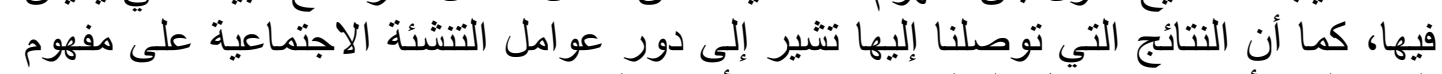

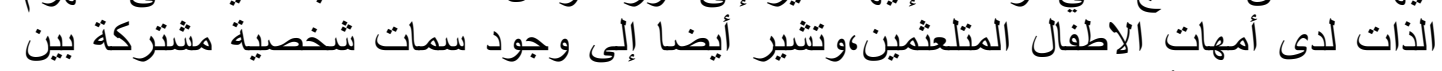

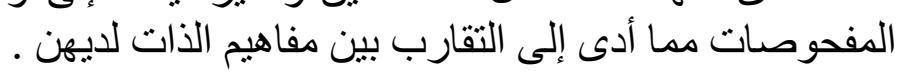

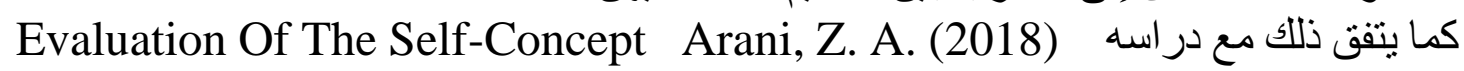
Of Mothers With Stuttering Children أمهات الأطفال المتلعثمين. هدفت الدر اسة إلى تقويم مفهوم الذات بين أمهات الأطفال المتلعثمين

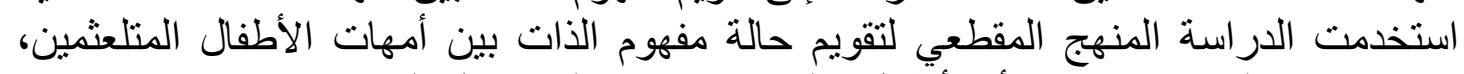

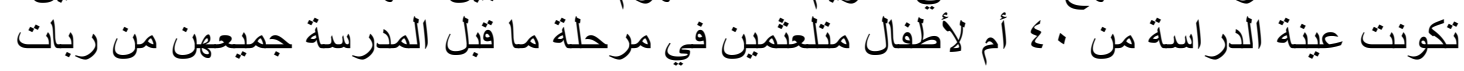

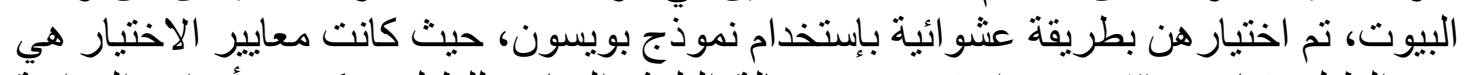

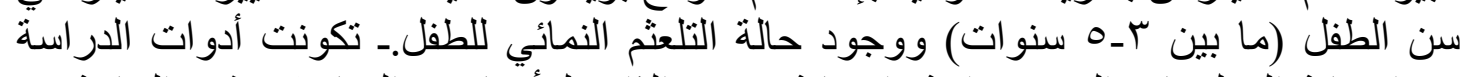

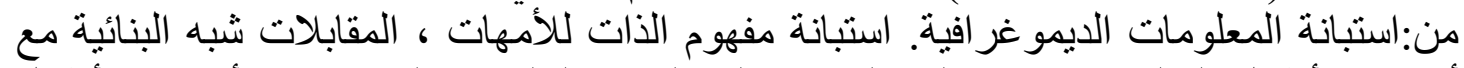

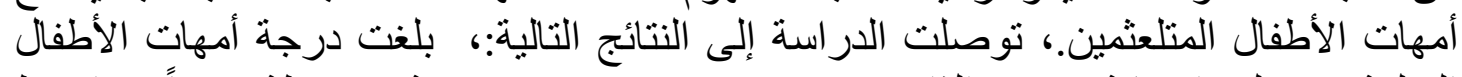

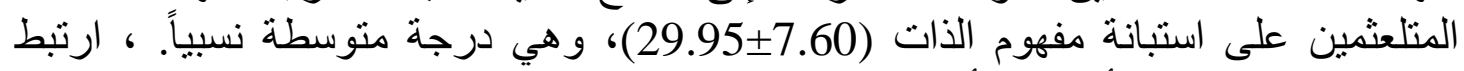

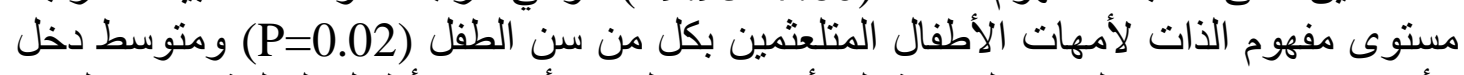

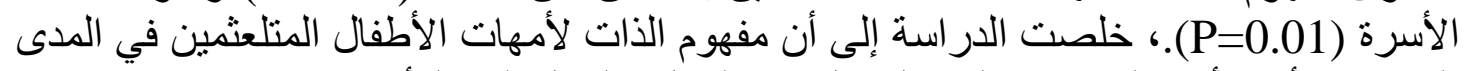

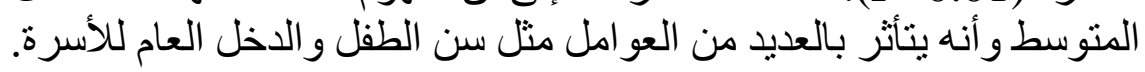

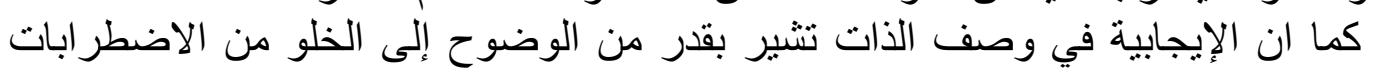

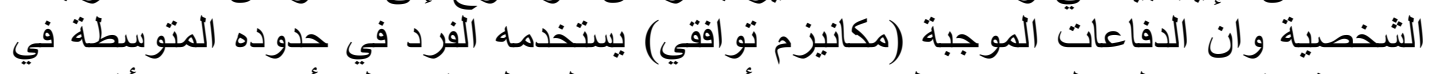

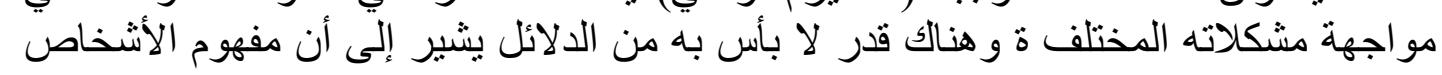

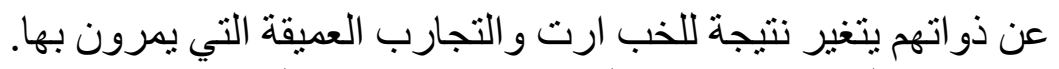

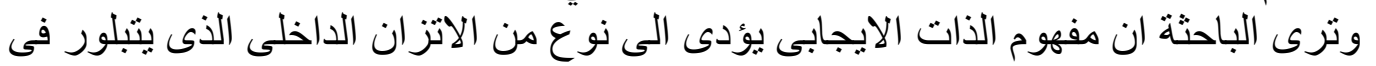

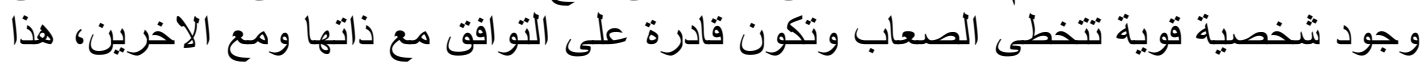

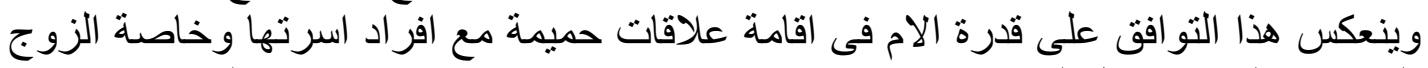

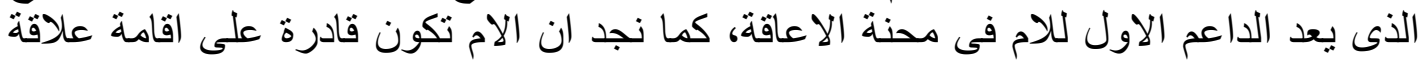

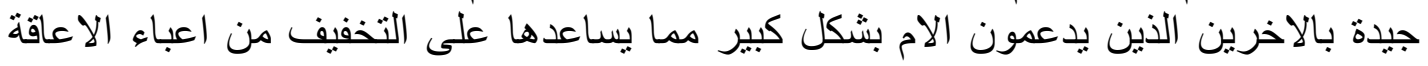

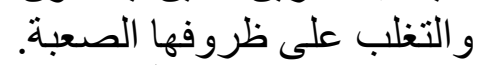
توصيات الار أسفة:

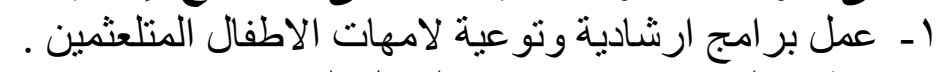

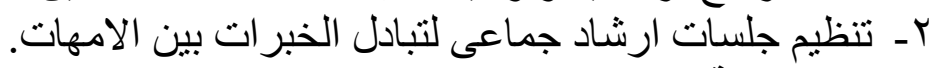

البحوث المقترحة:

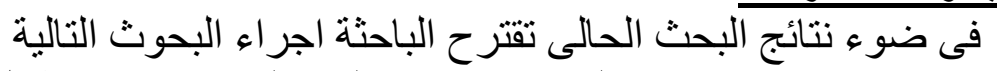

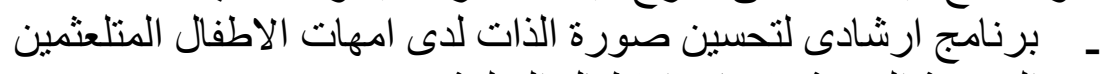

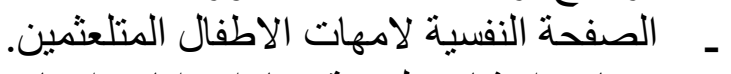

- برنامج ارشادى لتنمية مهار ات اباء و امهات الاطفات المنفين المتلعثمين ومساعدتهم فى رعاية 


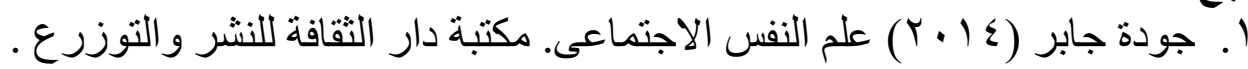

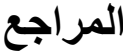

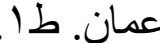

Y. سهير كامل ( • • (Y) التوجيه و الارشاد النفسى للصغار . مركز الاسكندرية

للكتاب. القاهرة.

r. شاكر المحاميد (10 1 ب) . علم النفس الاجتماعى .دائرة المكتبة الوطنية .عمان.طا.

دار صفاء للنشر

؟. . صفوت فرج وسهير كامل احمد (ع ( • ) مقياس تنسى لمفهوم الذات. الانجلو

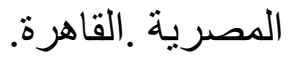

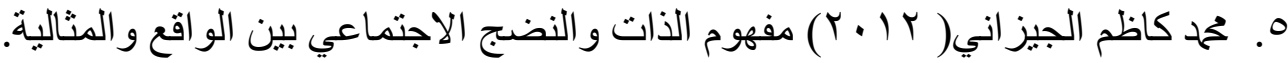

عمان . (2)

6. Arani, Z. A. (2018). Evaluation Of The Self-Concept Of Mothers

With Stuttering Children, Journal of Nursing and Midwifery

Sciences; 7 (3).

7. Blood, G. W., Blood, I. M., Tellis, G. M., \& Gabel, R. M. (2018). A preliminary study of self-esteem, stigma, and disclosure in parents of children who stutter. Journal of Fluency Disorders, 28(2), 143-159.

8. Bong, M., \& Skaalvik, E. M. (2019). Academic self-concept and self-efficacy: How different are they really? Educational Psychology Review, 15(1), 1-40.

9. Coleman, P. K. \& Karraker, K. H. (2018) Parents' self-concept among mothers of preschool-age children: conceptualization, measurement, and correlates. Family Relations, 49, 13-24.

10.Crncec, R., Barnett, B., \& Matthey, S. (2020). Review of scales of parenting self-concept, Journal of Nursing Measurement, 18(3), 210.

11.DesJardin, J. L. (2018). Maternal perceptions of self-concept and involvement in the development of young children with stuttering, Journal of Early Intervention, 27(3), 193-209.

12.El-Adawy, A. A. N.; Louis, K.; Emam, A. M.; Elbarody, Z. M., \& Mostafa, E. (2020). Attitudes towards stuttering of parents and other family members of children who stutter in Egypt, Speech, Language and Hearing, Speech, Language And Hearing; 7 (12).

13.Erickson, S., \& Block, S. (2019). The social and psychological impact of stuttering on children and their families. Journal of Fluency Disorders, 38(4), 311-324. 
14.Giallo, R., Wood, C. E., Jellett, R., \& Porter, R. (2017). Fatigue, wellbeing and parental self-concept in mothers of children with stuttering. Children Communication, 17(4), 465-480.

15.Gilmore, L., \& Cuskelly, M. (2019). Parenting satisfaction and self-efficacy: A longitudinal study of mothers of children who stutter, Journal of Family Studies, 18(1), 28- 35.

16.Gregg, B. A. (2020). Addressing core questions from parents of children who stutter, Clinical Archives of Communication Disorders; 5 (1)

17.Halpern, L. F., \& Mclean Jr, W. E. (2018). Hey mom, look at me!, Infant Behavior and Development, 20(4), 515-529.

18.Hartrick, G. A. (2018). Women who are mothers of stammering children: The experience of defining self. Health Care for Women International, 18, 263-277.

19.Jones, T. L. \& Prinz, R. J. (2017) Potential roles of parental selfefficacy in parent and child adjustment: a review. Clinical Psychology Review, 25, 341-363.

20.King, K. A. (2019). Self-concept and self-esteem: a clarification of terms. Journal of School Health, 67(2), 68-71.

21.Langevin, M., Packman, A., \& Onslow, M. (2019). Parent perceptions of the impact of stuttering on their preschoolers and themselves. Journal of Communication Disorders, 43(5), 407- 423.

22.Millard, S. K., \& Davis, S. (2018). The Palin Parent Rating Scales: Parents' perspectives of childhood stuttering and its impact on selfconcept. Journal of Speech, Language, and Hearing Research, 59(5), 950-963.

23.Nunes, C., \& Ayala-Nunes, L. Y. (2017). Parenting Sense Of Competence In At Psychosocial Risk Families And Child WellBeing, Bordón; 69 (1).

24.Oyserman, D., Elmore, K., \& Smith, G. (2019). Self, self-concept, and identity. In M. R. Leary \& J. P. Tangney (Eds.), Handbook of self and identity (pp. 69-104). New York, NY, US: Guilford Press. 